\title{
Adherence to medication among chronic patients in Middle Eastern countries: review of studies
}

A. Al-Qasem, ${ }^{1}$ F. Smith ${ }^{7}$ and S. Clifford ${ }^{1}$

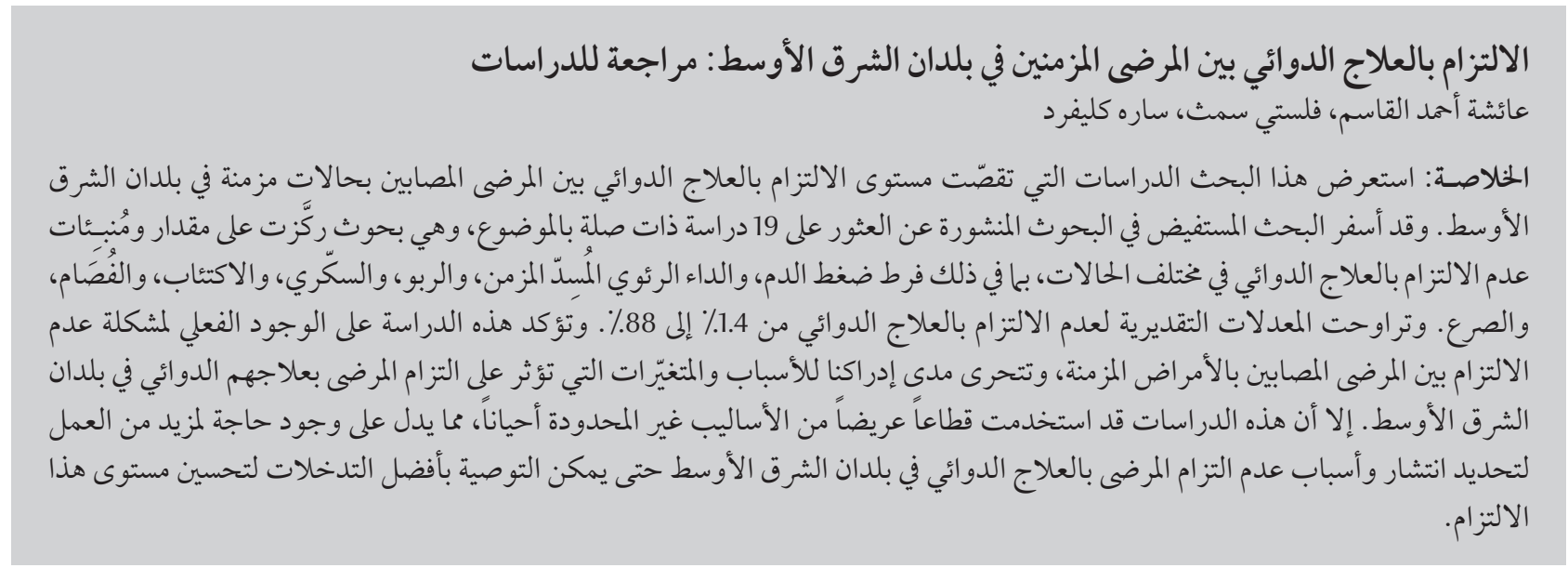

ABSTRACT This paper reviewed studies that have investigated adherence to medication among patients with chronic conditions in Middle Eastern countries. A comprehensive literature search yielded 19 relevant studies. These focused on the extent and predictors of nonadherence to medication across different conditions, including hypertension, chronic obstructive pulmonary disease, asthma, diabetes, depression, schizophrenia and epilepsy. Estimated rates of nonadherence to medication ranged from $1.4 \%$ to $88 \%$. This review confirms the existence of nonadherence as a problem among patients with chronic diseases and examines our understanding about the reasons and variables affecting patients' adherence to their medication in the Middle Eastern countries. However, the studies employed a wide range of methods, sometimes with limitations. Further work to determine the prevalence and causes of patients' nonadherence to medication in Middle Eastern countries is needed in order to recommend the best interventions to improve adherence.

Observance thérapeutique chez les patients atteints d'affections chroniques dans les pays du MoyenOrient : analyse de plusieurs études

RÉSUMÉ Le présent article a analysé des études ayant pour objet de recherche l'observance thérapeutique chez les patients atteints d'affections chroniques dans les pays du Moyen-Orient. Une recherche exhaustive de la littérature a permis de sélectionner 19 articles pertinents. Ces derniers étaient axés sur l'étendue de la non-observance thérapeutique et les facteurs prédictifs en la matière, par types de pathologies telles que I'hypertension, la bronchopneumopathie chronique obstructive, l'asthme, le diabète, la dépression, la schizophrénie et l'épilepsie. Les taux estimés de non-observance thérapeutique allaient de 1,4\% à $88 \%$. La présente analyse confirme l'existence d'un problème de non-observance chez les patients atteints d'affections chroniques et présente nos conclusions sur les raisons et variables influant sur l'observance thérapeutique des patients dans les pays du Moyen-Orient. Toutefois, les études analysées ont utilisé un large éventail de méthodes, et présentaient parfois des limites. Une recherche plus approfondie pour déterminer la prévalence et les causes de la non-observance des patients dans les pays du Moyen-Orient est nécessaire pour être en mesure de recommander les interventions les plus efficaces afin d'améliorer l'observance. 


\section{Introduction}

Adherence is defined by the World Health Organization (WHO) as "the extent to which a person's behaviourtaking medication, following a diet, and/or executing lifestyle changes corresponds with agreed recommendations from a health care provider" [1]. Nonadherence remains a major problem in patient care, despite the large number of research studies that have been conducted in this area in recent decades. Patients' poor adherence to their medication is a complex problem for health care services, especially in the care of chronic illness, for which the correct, effective treatment is essential for a patient's quality of life and survival rate. Failure to take the appropriate drug regimen as recommended may lead to poor therapeutic outcomes, wasted health care resources and inappropriate changes to treatment by prescribers.

A report by the WHO estimated that the average rate of adherence to medication is around $50 \%$ among patients suffering from chronic diseases in developed countries, and this is assumed to be lower in developing countries where there is limited access to health care and medicines [1]. Although there might be similarities in the rate and reasons for nonadherence in the Middle East compared with the rest of the world, there may also be important differences. This is because reasons for nonadherence are complex. They are affected by operational factors in the health care system (including access to medicines), by relationships between health care professionals and patients, by cultural perceptions about the use of medication and by patients' beliefs.

The aim of this paper was to review the relevant research into adherence to medication regimens among patients with chronic conditions in the Middle East region. The objectives were to establish the extent to which adherence to medication regimens has been studied in this region of the world, and review evidence regarding adherence rates, the reasons for nonadherence and the variables found to influence adherence/ nonadherence behaviours.

\section{Search strategy}

A systematic search of studies related to medication adherence in chronic diseases in the Middle East region was performed using the following databases: EMBASE, MEDLINE, PSYCHINFO, CINAHL, PubMed, International Pharmaceutical Abstracts and the Web of Knowledge. The search terms were: (adherence or compliance AND therapeutic alliance or nonadherence to medication or therapy refusal AND Middle East or United Arab Emirates or Saudi Arabia or Kuwait or Bahrain or Qatar or Oman or Jordan or Egypt), with or without the combination of the keywords: (treatment or regimen). A further search with the Google search engine was carried out to identify all health care and clinical journals in Middle East countries. All journals were searched for relevant papers and the citations of relevant papers were hand searched for further articles.

All the studies were analysed for their findings and the quality of the research. In this review, the definition or classification (level) of adherence, study setting, population and sampling, methods of data collection and measurement of adherence were taken into account.

\section{Results}

A total of 19 studies were identified from all regions of Middle East (Table 1): Egypt (4 studies), Sudan (1), Libyan Arab Jamahiriya (1), Saudi Arabia (6), Kuwait (3), United Arab Emirates (1), Palestine (1), Turkey (1) and Pakistan (1). Of the studies 17 were conducted among adult populations and 2 among children $[2,3]$.
The studies focused on different disease and illness groups, including hypertension [4-10], diabetes [11-14], mental illness [15-17], asthma $[3,18]$, epilepsy $[2,19]$ and chronic obstructive pulmonary disease [20]. They were conducted in primary health care centres, outpatient clinics and diabetes centres.

The sample sizes ranged from 104 to 1000 , with a median of 278 patients.

\section{Measures employed for data collection on adherence to medication}

Adherence to medication was measured using self-reports, pill counts and outcome measures. Almost all of the studies (17 of 19) used patients' self-reporting either alone $[2-7,11,12,14,17,18,20]$ or combined with other methods, especially pill counts $[8,9,13,15,16]$. In one study of epileptic patients pill counts only were used [19] and in another study of hypertensive patients pill counts were combined with blood pressure measurements [10].

In 12 studies self-reports were obtained using structured questionnaires $[2-6,9,11,12,14,17,18,20]$. Two studies $[4,5]$ used a previously validated measure: the Morisky medication adherence scale [21]. However, in 1 of these studies [4] details were not provided on the translation or crosscultural validity of the tool. In another 2 studies, the authors reported that they had adapted a questionnaire from earlier relevant published studies [18] or from a medical textbook [6], but details of this adaptation process were not provided.

In 7 studies, respondents were directly asked about their adherence to medication, e.g. the total number of tablets they had been prescribed per week and how many pills they took and missed in the last 3, 5 and 7 days [4] or previous month [7] or whether they had taken their medication as directed by the physician $[13,15,16,19]$ 
or whether they were taking their drugs regularly or not [8].

In 4 studies, questionnaires were administered by the patient's physician [3,11-13].

\section{Definition or classification (level) of adherence/ nonadherence}

Different definitions of adherence or nonadherence were employed; 14 studies provided information on these definitions.

In 6 studies patients were considered to be adherent if they reported taking $\geq 80 \%$ of their doses as prescribed $[4,5,8,10,15,16]$. In a further study the cutoff used was $75 \%$ [14]. In another study, adherent patients were those who used their medication correctly (knowledge about at least 2 of their bronchodilator medication doses and correct inhalation technique) and regularly (every day) [20]. In 1 study the doctors made a judgement about patients' compliance based on their answers to questions, the details of which were unspecified in the paper [3].

Conversely, nonadherence was defined variously as: missing a total of 1 day of doses/week [2], or $<90 \%$ of their pills [7], or 4 doses per month [13] or a total of 3 days' doses/month [19]. One study did not report actual values but instead defined nonadherence as "failure to take medications as prescribed for a period greater than a week" [17].

\section{Adherence/nonadherence rates}

Overall, the estimated rates of nonadherence to medication in these Middle East countries ranged from $1.4 \%$ and $88 \%$ in the different studies. Studies in which questionnaires were completed by the patient's physicians tended to report low nonadherence rates compared with the other studies $[3,11,13,15]$. In one study in which data on adherence were collected both by patients' selfreports and by physicians, the physicians overestimated the level of their patients' adherence to medication; physicians estimated the nonadherence rate as $29 \%$, whereas patients' self-reports gave an estimate of $48 \%$ [5].

Within the same illness group, 7 studies among hypertensive patients reported medication nonadherence rates between $23 \%$ and $49.5 \%$ and 4 studies among diabetic patients reported nonadherence rates between $1.4 \%$ and $27.1 \%$. However, 2 studies conducted with patients with depression reported nonadherence rates of $24 \%$ to $30 \%$ in one study [16] and $88 \%$ in another [15].

\section{Reasons for nonadherence}

A wide range of reasons were given by patients for nonadherence to medications. These included: forgetfulness $[2,7,10,15,18,19]$, drug side-effects $[7,10,15,17,19]$, wanting a "drug holiday" [7], concerns about drug dependency $[15,17]$, feeling well $[7,10,15,18]$, medication was not helping them feel better $[15,18]$, irregularity of follow-up [9], lack of health education [10], shortage of drugs $[10,19]$, unawareness of the chronicity of the disease [20], busy parents [2], not having been told to continue the treatment [19], disbelief about the value and need for adherence [19], social stigma [17], complexity of the treatment regimen [17], inability to see their usual doctor [15], only using the medication as needed [18], feeling better (with bronchodilators) [18], inability to afford the drugs [8] and feeling lazy [18].

\section{Discussion}

The results of this review indicate that, as elsewhere in the world, there is a problem of nonadherence to medication among patients with chronic conditions in a number of Middle Eastern countries. However, caution must be taken before drawing a conclusion about the rate of nonadherence due to the wide discrepancy in the estimates of nonadherence rates between these studies, which varied from $1.4 \%$ to $88 \%$. This variation could be due to the different disease conditions studied, different patient populations, differences in the definitions ofadherence/nonadherence to medications used or to differences in the methods employed. All methods of measurement have their advantages and limitations and therefore there is no "gold standard" for the assessment of adherence.

The nonadherence rate was higher among hypertensive patients than those with diabetes, which could be due to the nature of hypertension disease (asymptomatic) or to different perceptions of the seriousness of the condition. Also findings from a small number of studies must be viewed with caution. This is supported by the international literature, as WHO reports [1] that estimates of the extent to which patients adhere to pharmacotherapy for hypertension vary from $50 \%-70 \%$, compared with an estimated 36\%-93\% adherence to hypoglycaemic agents [22].

The 4 studies where interview-based questionnaires were administered by physicians reported lower nonadherence rates compared with other studies, ranging from $1.4 \%$ to $27.1 \%[3,11-13]$. This could be as a result of patients exaggerating their degree of medication adherence to their treating physician for fear that admitting poor adherence would affect the quality of care they would receive or to gain their physician's approval.

Many variables were suggested to affect patients' adherence to their medication (Table 1), but there were some contradictory results. For example, in 2 studies nonadherence was shown to be higher in younger patients $[9,17]$ and in 1 study it was higher in older age groups [10].

The reasons reported by patients for nonadherence to their medication varied across the studies but the 2 most frequently reported reasons were 


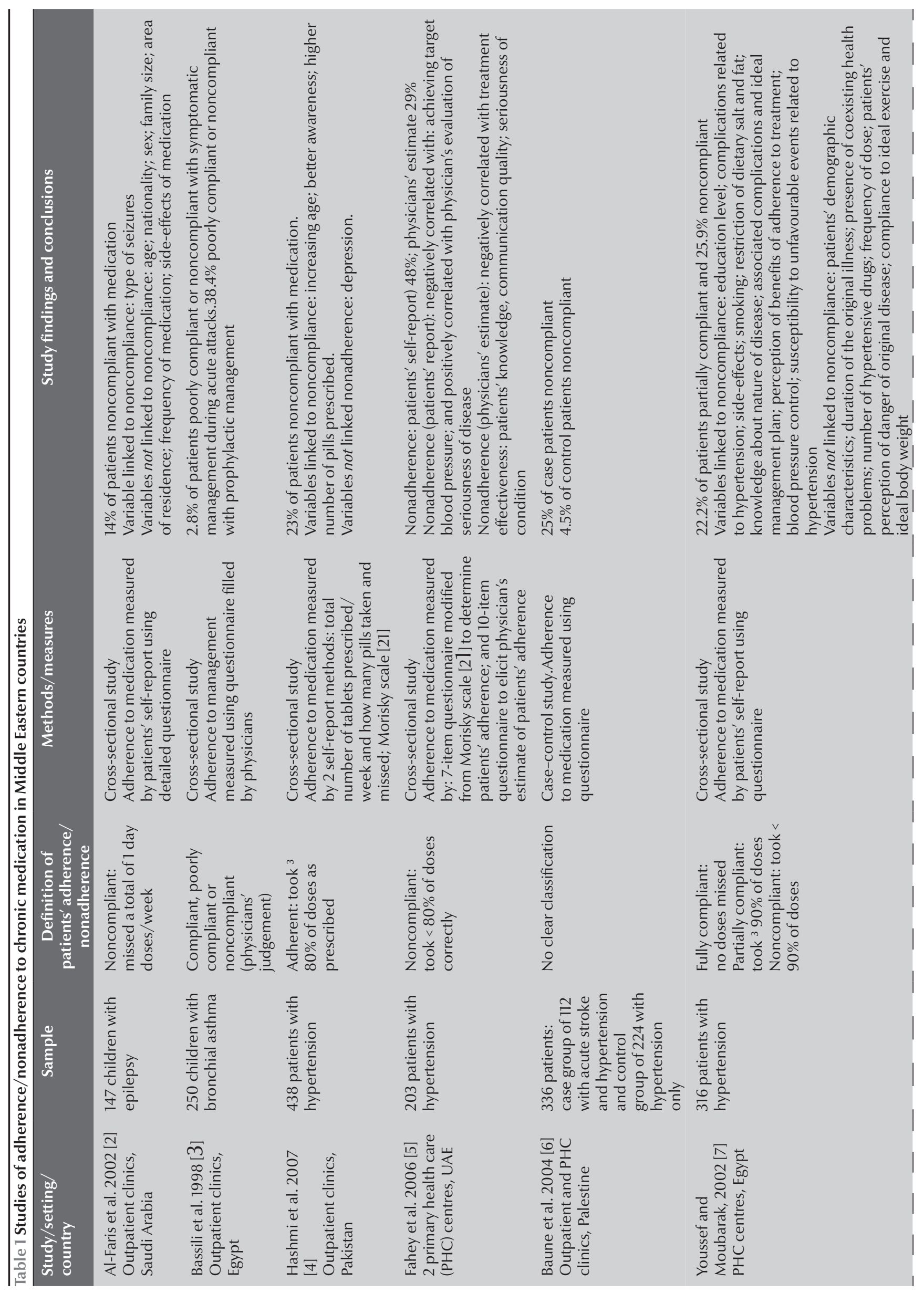




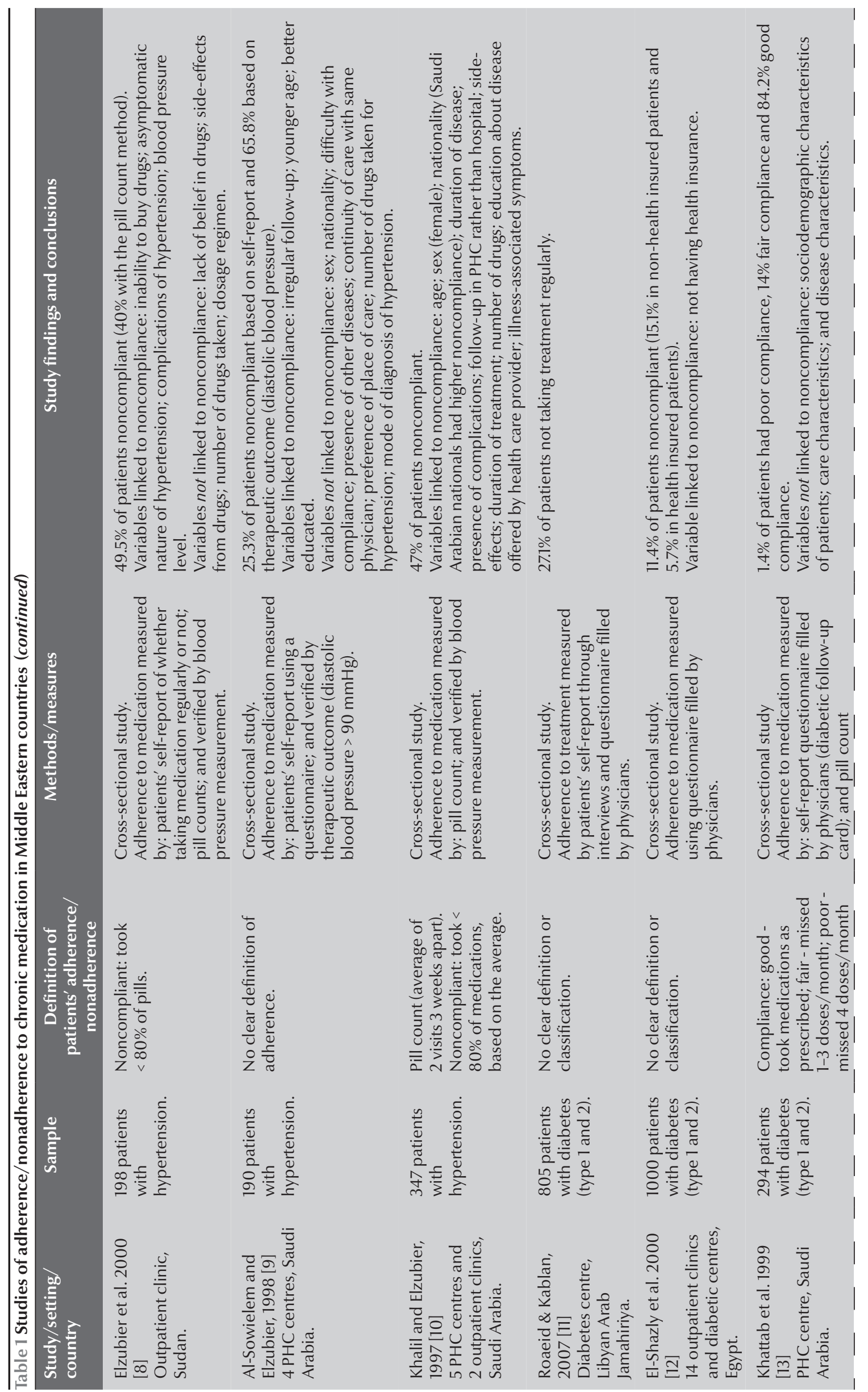




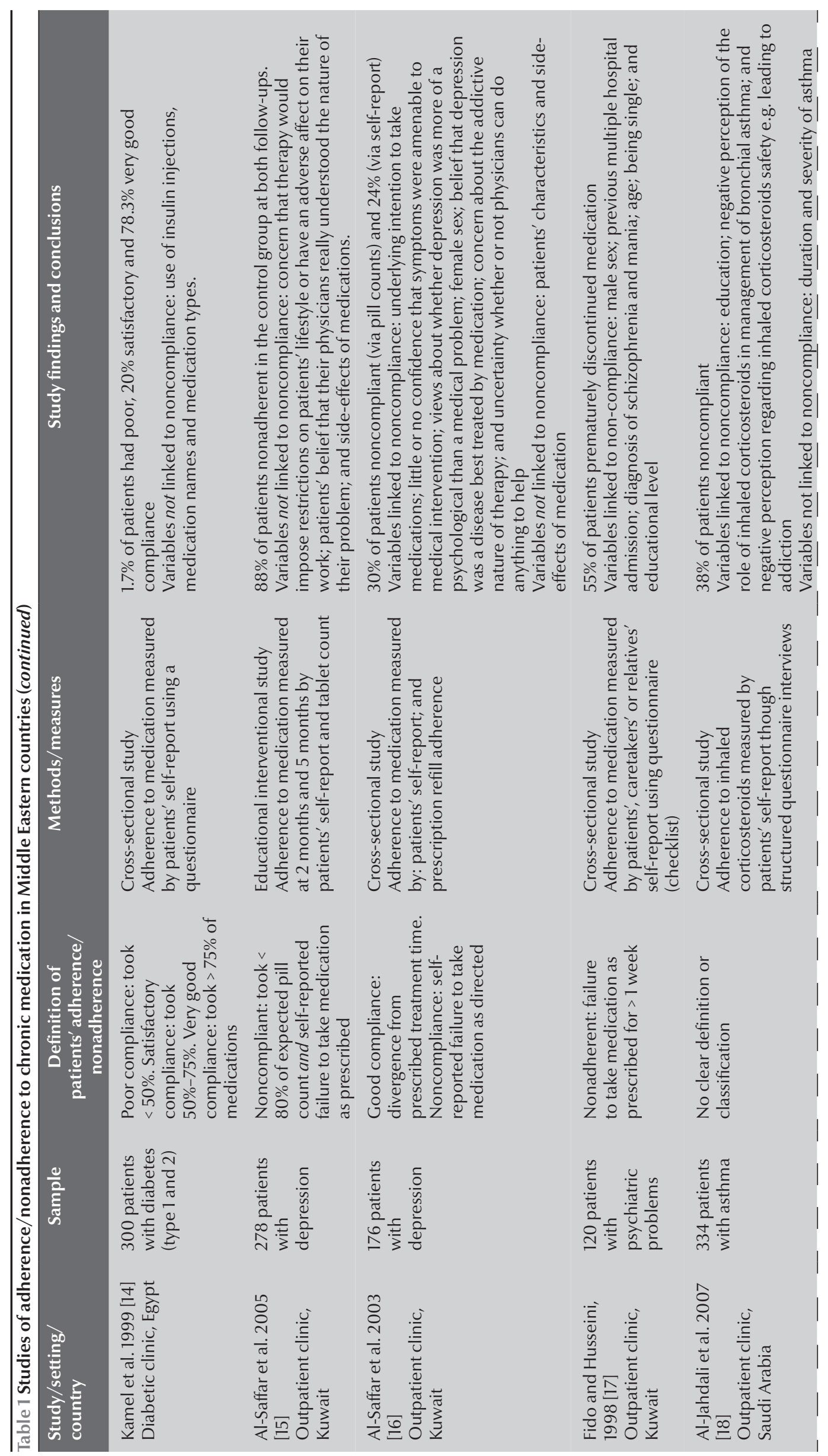




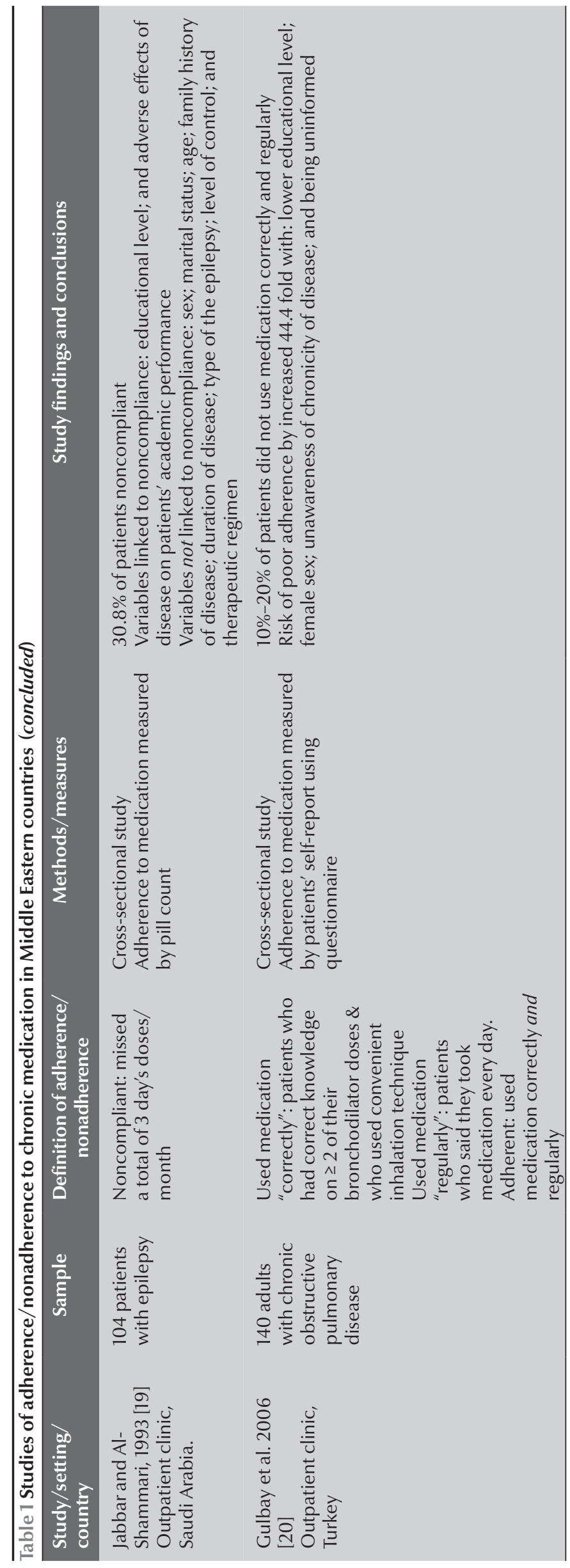

forgetfulness (6 studies) and drug side-effects (5 studies). The reasons reported by patients in the Middle East are similar to those reported in the international literature. However, some common reasons reported by the international literature were not reported by these patients, such as patient satisfaction and/or lack of trust in health care providers and lack of social support. The reason for this could be that patients in the Middle East may be more afraid to complain about their doctors in order to avoid problems that might compromise their treatment. These studies were not designed to explore barriers to medication adherence (intentional/nonintentional) and beliefs about the perceived value of medication and concerns regarding side-effects. There is a need for a more qualitative approach to explore how factors such as the context of the health care system, access to medication and beliefs affect nonadherence to medication for patients with chronic illness in the Middle East.

\section{Limitation of the review}

The literature search found only 1 article through databases searches and the rest were found by hand searching. Therefore some relevant papers in this field could have been missed. Although most of the journals in the Middle East publish in English language, studies published in other languages may have been missed papers as only English language papers were included in the search.

\section{Conclusions}

This review confirms the existence of nonadherence to medication as a problem among patients with chronic diseases in the Middle East. However, there was great variation in the reported rates of nonadherence, probably due to differences in the definitions of adherence/nonadherence used as well as other differences in the study methods. Some barriers and predictors of nonadherence among patients in this region were identified. However, these 19 studies did not enable meaningful conclusions regarding level of adherence to be drawn. The review findings highlight the need to expand this area of research in the region and to improve the quality of such research. Therefore, there is a need for further research on the rate of nonadherence and barriers to patients' adherence to their medications in order to identify the type of interventions that may be needed for improving adherence. 


\section{References}

1. Adherence to long-term therapies: evidence for action. Geneva, World Health Organization, 2003.

2. Al-Faris EA et al. Compliance with appointments and medications in a pediatric neurology clinic at a University Hospital in Riyadh, Saudi Arabia. Saudi Medical Journal, 2002, 23:969-974.

3. Bassili A et al. Current health care of childhood bronchial asthma in Alexandria, Egypt. Eastern Mediterranean Health Journal, 1998, 4:575-584.

4. Hashmi SK et al. Factors associated with adherence to antihypertensive treatment in Pakistan. PLoS ONE, 2007, 2:e280.

5. Fahey $\mathrm{M}$ et al. Measurement of adherence to anti-hypertensive medication as perceived by doctors and patients. QatarMedical Journal, 2006, 15:1-11.

6. Baune BT, Aljeesh YI, Bender R. The impact of non-compliance with the therapeutic regimen on the development of stroke among hypertensive men and women in Gaza, Palestine. Saudi Medical Journal, 2004, 25:1683-1688.

7. Youssef RM, Moubarak II. Patterns and determinants of treatment compliance among hypertensive patients. Eastern Mediterranean Health Journal, 2002, 8: 579-592.

8. Elzubier AG et al. Drug compliance among hypertensive patients in Kassala, eastern Sudan. Eastern Mediterranean Health Journal, 2000, 6:100-105.

9. Al-Sowielem LS et al. Compliance and knowledge of hypertensive patients attending PHC centers in Al-Khobar, Saudi Arabia. Eastern Mediterranean Health Journal, 1998, 4:301-307.

10. Khalil SA, Elzubier AG. Drug compliance among hypertensive patients in Tabuk, Saudi Arabia. Journal of Hypertension, 1997, 15:561-565.

11. Roaeid RB, Kablan AA. Profile of diabetes health care at Benghazi Diabetes Centre, Libyan Arab Jamahiriya. Eastern Mediterranean Health Journal, 2007, 13:168-176.
12. El-Shazly $M$ et al. Health care for diabetic patients in developing countries: a case from Egypt. Public Health, 2000, 114:276-281.

13. Khattab MS et al. Compliance and control of diabetes in a family practice setting, Saudi Arabia. Eastern Mediterranean Health Journal, 1999, 5:755-765.

14. Kamel NM et al. Sociodemographic determinants of management behaviour of diabetic patients. Part I. Behaviour of patients in relation to management of their disease. Eastern Mediterranean Health Journal, 1999, 5:967-973.

15. Al-Saffar $\mathrm{N}$ et al. Effect of information leaflets and counselling on antidepressant adherence: open randomised controlled trial in a psychiatric hospital in Kuwait. International Journal of Pharmacy Practice, 2005, 13:123-132.

16. Al-Saffar $\mathrm{N}$ et al. Health beliefs and drug compliance of depressed patients in Kuwait. Journal of Social and Administrative Pharmacy, 2003, 20:142-150.

17. Fido AA, Husseini AM. Noncompliance with treatment among psychiatric patients in Kuwait. Medical Principles and Practice, 1998, 7:28-32.

18. Al-Jahdali $\mathrm{HH}$ et al. Perception of the role of inhaled corticosteroids and factors affecting compliance among asthmatic adult patients. Saudi Medical Journal, 2007, 28:569-573.

19. Abdul Jabbar M, Al-Shammari SA. Compliance in Saudi epileptic patients: Determinants of compliance in Saudi epileptic patients. Annals of Saudi Medicine, 1993, 13:60-63.

20. Gulbay BE et al. Patients adherence to treatment and knowledge about chronic obstructive pulmonary disease. Saudi Medical Journal, 2006, 27:1427-1429.

21. Morisky DE, Green LW, Levine DM. Concurrent and predictive validity of a self-reported measure of medication adherence. Medical Care, 1986, 24:67-74.

22. Cramer JA. A systematic review of adherence with medications for diabetes. Diabetes Care, 2004, 27:1218-1224. 